\title{
MOISÉS BEN ZEMERRO, ALIAS DON PABLO DE SANTA MARÍA
}

\author{
Hossain Bouzineb*
}

Antes que nada, convendría hablar de la poca eficacia que tuvieron los puertos de Larache y la Mamora, ocupados por los españoles en 1610 y 1614 respectivamente, para atajar el endémico mal que afectaba a los españoles a causa de la actividad corsaria desarrollada en el Atlántico, sobre todo tras la llegada de los moriscos expulsados en 1610 al estuario del Buregreg y su instalación en la mencionada alcazaba. De tal situación surgió más de un deseo de aprovechar la coyuntura, proponiendo a los españoles, así como a otras naciones, variadas propuestas $^{1}$ para hacerse con este nuevo punto problemático. La primera de tales ofertas, hechas a los españoles, tuvo lugar en 1614, inaugurando de este modo una larga serie que jalonará prácticamente todo el medio siglo que seguirá la instalación de los moriscos en este lugar. La mencionada propuesta inaugural provino de un judío converso tetuaní, llamado Juan Ludovico Rodrigo; después seguirá, en 1619, la que se relaciona con nuestro personaje, también judío converso; y en el mismo año otra procedente de un morisco.

Al intentar averiguar quién fue este don Pablo de Santa María, damos con varias noticias mencionadas en diferentes obras que podrían encaminarnos hacia la finalidad que buscamos. En primer lugar, hemos de decir que se trata de un judío marroquí de Fez, de origen hispano, llamado Moisés ben Zemerro, convertido al catolicismo y bautizado con el nombre de Pablo de Santa María, a la edad de cuarenta años, en el Escorial el 3 de abril de $1589^{2}$. Llama nuestra atención la existencia de un homónimo de nuestro personaje, pero de muchísimo más relieve, también judío converso, que se llamaba Solomon Ha-Levy, nacido en Burgos hacia 1351 y fallecido el 29 de agosto de 1435, llegando a ser obispo de Cartagena y de Burgos, y encargado de importantes misiones por el rey y el papa $^{3}$. Las coincidencias en el origen, nombre y conversión, nos conducen a plantear una probable admiración e identificación de Moisés ben Zemerro con la

\footnotetext{
* Universidad Mohammed V de Rabat.

1. Véase nuestro Alcazaba del Buregreg, hornacheros, andaluces, y medio siglo de designios españoles frustrados, Rabat, 2006.

2. Cfr. Hespéris, XXIV, 1937, p. 136.

3. Véase su semblanza en Wikisource.
} 
personalidad del mencionado obispo, a la hora de tener que adoptar un nombre cristiano después de abrazar la nueva religión. Si verdaderamente esta fue la razón de la adopción del nuevo nombre por el neófito, podríamos descubrir un rasgo más de la personalidad de Moisés de Zemerro, sobre todo si atendemos a lo que nos dice Salvador de Madariaga de Solomon Ha-Levy, al considerar que "Don Pablo de Santa María fue el jefe indiscutible del antisemitismo español en el siglo XV"4; o lo que nos cuenta Manuel L. Ortega, autor de Los Hebreos en Marruecos al decir que "Un convertido, Pablo de Santa María, influyó sobre la reina viuda de Enrique III, regente durante la minoría de su hijo Juan II, para que continuase la política de persecución de los hebreos..." ${ }^{5}$.

Hay que señalar que la familia Zemerro ${ }^{6}$ constituía uno de los principales linajes de origen hispano ${ }^{7}$ que se instalaron en Fez, Safí y otras ciudades de Marruecos, además de haber emigrado a otros lugares como sucedió con David ben Zemeró, que fue rabino en El Cairo en el siglo XVI ${ }^{8}$.

Algunos extremos acerca de quién fue este judío marroquí nos los suministra Isaac Almosnino, otro judío de Fez, detenido en Goa (en la India) y presentado ante la Inquisición, que al ser preguntado "si conoce judíos que se hayan convertido al cristianismo, menciona a varios convertidos en Tánger en tiempos de Don Alfonso de Noronha, como los hermanos Camondo, Abraham Gibre, Moysen ben Zamerro. Y que todos estos le conocen a él y muy bien"

De esto último inferimos que la mencionada conversión que lleva a cabo en Tánger, a la sazón bajo dominio portugués, probablemente debió constituir el preludio de la andada de Moisés ben Zemerro por la Península Ibérica, así como suponer también una continuación de una práctica familiar de ofrecer servicios a los portugueses ${ }^{10}$. En adelante veremos que llega a prestar tales servicios al propio rey don Sebastián para la toma de Arzila, antes de que éste acometiera la aventura de Alcazarquivir en la que perdió la vida en 1578. Parece que muchos años antes de protagonizar lo de la alcazaba de Salé, debió de llevar a cabo una gestión encomendada por don Sebastián con ocasión de los preparativos para la

4. Salvador de Madariaga, La vida del muy magnífico señor Don Cristóbal Colón (5ª ed.), México, 1979, p. 178.

5. Manuel L. Ortega, Los Hebreos en Marruecos, estudio histórico, político y social, Madrid, 1919, p. 77.

6. Véanse ciertos detalles de la historia de esta familia judía en: Catherine GARSON, «Zmirro, les chanteurs de Zamora», en Racines: L'Origine des noms juifs, L'Arche, 519, 2001 (http: / / www.col.fr/arche/ racine519.htm).

7. M. García-Arenal y G. Wiegers, Entre el Islam y Occidente, vida de Samuel Pallache, judío de Fez, Madrid, p. 75.

8. Manuel L. Ortega, op. cit., p. 118.

9. M. García-Arenal y G. Wiegers, op. cit., pp. 73-74.

10. Otro pariente de Moisés estaba también muy relacionado con los portugueses, como bien recoge el mencionado documento que relata su bautismo en el Escorial: "On peut avec plus de certitude le rapprocher d'Abraõ Benzemerro, qui, en 1538, était en relations avec les capitaines portugais d'El-Qșar es-Ṣgir, de Tanger et d'Arzila". 
batalla de Alcazarquivir. Dado que "antes de embarcarse en la aventura D. Sebastián estuvo en Äfrica, tomando posesión de Arcila, que se entregó voluntariamente"11. Justamente, con esta ocasión, declara don Pablo de Santa María que: "se fió de mí sólo el secreto de la entrega de la villa de Arcilla, al Rey D. Sebastián que aya gloria. La qual se hizo sin costar una sola pequeña gota de sangre, de que yo daré muy buena relación, porque fui a todo presente" ${ }^{\prime 12}$.

Nos imaginamos que tras el descalabro sufrido por los portugueses, Moisés ben Zemerro fue a probar fortuna en el país vecino y a ofrecer sus servicios al rey de España, con negocios de la misma naturaleza que los ya acostumbrados. Entonces debió renovar su conversión en el Escorial, como mencionamos más arriba.

Los negocios que quiere protagonizar don Pablo de Santa María pasan necesariamente por manos del duque de Medina Sidonia, y a éste parece que no le caía bien el judío converso. Quizá hasta lo despreciaba y no se fiaba de lo que pretendía llevar a cabo. Don Pablo de Santa María, muy resentido del trato que le guardaba el duque, se queja ante el rey:

"Por una carta que tuve del Secretario Juan de Çiriça de 13 deste [que me halló con una fuerte terçiana, cauzada sólo de pezadumbre de verme en San Lucar tantos días sin aver conclusión en cosa de tanta ymportançia y que requiere tanta brevedad] supe cómo Vra. Real Mgd. estima, en lo que ellos mereçen mis buenos serviçios, y que Vra. Real Magd. me haze md. de otros duzientos ducados de ayuda de costa; por tales ms. [=mercedes] y onras bezo la tierra debaxo de los pies de Vra. Magd., mas no puedo dexar de dezir que me vino muy aguada y aún amargosa, porque aviéndome Vra. Magd. en muchos previlegios nombrado por don Pablo de Santa $\mathrm{M}^{\mathrm{a}}$. y aún el propio Juan de Çiriça tanbién, en la carta que yo truxe suya para el duque, agora en el sobrescrito desta carta dize a Pablo de Santa $\mathrm{M}^{\mathrm{a}}$., cosa que he sentido mucho, porque en las cosas umanas, lo que más estimo es la onra, y pues nro. Señor Jhesu Cristo se me dio a sí propio, y me dio por padrino a Vra. Real Magd. le suplico omilde mente se sirva de onrarme, porque lo estimaré en muy grande $\mathrm{md}^{\prime 13}$.

Así, pues, al desposeerle el duque del tratamiento de respeto con "Don" que, según el Diccionario de la Real Academia, "antiguamente estaba reservado a determinadas personas de elevado rango social", nuestro judío converso, que se consideraba como perteneciente a tal rango, ve en la mencionada actitud de Medina Sidonia, a la que se añade el haberle hecho esperar tantos días sin recibirle en Sanlúcar, una profunda humillación.

¿En qué consistía la propuesta en la que aparece inmiscuido don Pablo de Santa María? Como más arriba indicamos, en las costas atlánticas marroquíes se vivía una situación embarazosa para España a causa de la creciente actividad

11. Cfr. L.I. Álvarez De Toledo, La anexión de Portugal. INTERNET.

12. Ibid.

13. Cfr. el documento n. ${ }^{\circ} 13$ en nuestro Alcazaba del Buregreg, anteriormente citado. 
corsaria que seriamente le dañaba y que había que remediar de alguna manera. Los esfuerzos que habían sido desplegados con tal finalidad, ocupando Larache y la Mamora, no dieron los frutos que de ellos se esperaba, al surgir el nuevo foco corsario de Salé, que cada día que pasaba no hacía sino crecer. En este contexto, hemos de confesar que todavía no comprendemos las verdaderas razones que impulsaron a los distintos protagonistas de este fallido proyecto de cesión de la estratégica alcazaba de Salé a presentar una propuesta a los españoles para ocupar la mencionada alcazaba.

Los protagonistas del proyecto fueron nada más y nada menos que el célebre combatiente al ‘Ayyāšĩ y los jeques y alcaides de la fortaleza:

"La carta de Ayax y de los Jeques y Alcaides de Zalé se reducían a que Su Magd. tenía pronosticado avía de Reinar en el Algarve y que quería irse el Moravito Ayax. Y no lo ponía en exon. [=ejecución] por estar muy empeñado y pedía le favoreciese Su Magd. y lo haría. Los xeques y Alcaides de Zalé ofrecieron la entrega de la fuerça; y para esto vino el moro el qual dixo que no tenía de término más de 20 días para tratar desto.

Don $\mathrm{P}^{\mathrm{o}}$. de Toledo oyó al moro que le habló en la misma sustancia de la profecía y de dar a Su Magd. la obediencia en nombre del alcaide y ofrécele un gran thesoro. Y discurre largamente sobre la convenencia [sic] de tener plaças en la costa de Bervería"14.

Se envía al moro Sidi 'Isa a la Mamora para negociar el asunto: "se resolvió que para volverse el moro se le diese una cadena de 500 Dos.; una sarta de perlas para su muger de 300 y cien doblones, y que fuese con él Don Pablo de Sta. María, intérprete, llevando entendido la forma de cómo se havía de tratar el negocio" (doc. $\mathrm{n}^{\circ} 31$ ).

Deducimos que Sidi 'Îsā ben Aţ̧̧āilb, que fue enviado para negociar en nombre de al-'Ayyāšñ y demás dignatarios de Salé, de repente cambió de parecer y se puso a negociar en nombre propio, planteando sus personales designios, probablemente influido por el intérprete don Pablo de Santa María que le acompañó y que dice le dio "muy buenos y saludables conçejos".

De todos modos y debido a las presiones del plazo fijado para cerrar el acuerdo (ya que el enviado, para no levantar sospechas, poseía un plazo bien fijo del que no tenía que exceder, además debía emprender un complicado itinerario para evitar que se le viera entrar en la Mamora) y de otros factores silenciados o que ignoramos, la propuesta se frustró dejando un mal sabor de boca a los que habían confiado en la viabilidad de la misma. Véase cómo se describe el final:

“... el moro se fue y el yntérprete se quedó en la Mamora donde avrá echo meses que murió, y hasta aora el dgo. moro no ha escrito ni dado c(uen)ta de sí, aunque el m(aest)ro de canpo Xpoval Lechuga en su vida la dio de su llegada, y

14. Cfr. el documento n. ${ }^{\circ} 31$ en nuestro Alcazaba del Buregreg. 
dijo que al principio avía sido mal r(ecibido)do de los suyos, porque se tuvo sospecha de la propuesta que vino a hazer. $Y$ de modo muy en particular dio q(üen)ta a Su Md. por el Cons(ej)o de Estado y m(inistr)o de Es(tad)o y $\mathrm{m}^{\circ}$ del $\mathrm{S}\left(\right.$ ecretari)o $\mathrm{Ju}^{\circ}$ de Çiriça, en cuyo poder se hallava la R(elaci)ón de lo que en el caso se ofreçió. Y después no se ha buelto a hablar en él, advirtiendo a V Md. que desde su principio tuve este neg(oci)o por cossa perdida y sin fundam(en)to como entonces lo dije".

\title{
RESUMEN
}

Moisés de Zemerro, o don Pablo de Santa María, es un personaje que en 1619 se ve asociado a un curioso proyecto que tuvo por designio ocupar la alcazaba de Rabat, designada Salé o alcazaba de Salé por la documentación europea del siglo XVII. La personalidad de este hombre merece realmente una indagación a fin de aclarar, o por lo menos comprender, la curiosidad de las peripecias que rodearon el mencionado proyecto.

Palabras clave: Moisés de Zemerro, Pablo de Santa María, Salé.

\begin{abstract}
Moises de Zemerro, or Don Pablo de Santa Maria, is a character that appears in 1619 involved in a surprising project the objective of which was to occupy the Alcazaba in Rabat, called Salé (or Alcazaba de Sale), according to the European documents of the 17 th $\mathrm{C}$. The personality of this man deserves some research in order to understand the course of events involving him and the mentioned project.
\end{abstract}

Key words: Moisés de Zemerro, Pablo de Santa María, Salé. 